\title{
Polytungstozincate Acid: A New and Efficient Catalyst for the Synthesis of Xanthenes Under Solvent-Free Conditions
}

\author{
Mostafa Mohammadpour Amini*, Yousef Fazaeli, Zahra Yassaee, Shahzad Feizi and \\ Ayoob Bazgir*
}

Department of Chemistry, Shahid Beheshti University, G.C., Tehran 1983963113, Iran

\begin{abstract}
Polytungstozincate acid was prepared from sodium polytungstozincate and after formulation, $\mathrm{Na}_{3} \mathrm{H}_{9}\left[\mathrm{WZn}_{3}\left(\mathrm{H}_{2} \mathrm{O}\right)_{2}\left(\mathrm{ZnW}_{9} \mathrm{O}_{34}\right)_{2}\right]$, was used as an efficient catalyst for the synthesis of xanthene derivatives under solventfree conditions. The simple experimental procedure, short reaction times (40-120 min.), and excellent yields (81-94\%) are the advantages of the present method.
\end{abstract}

Keywords: Xanthenes, solvent-free, polyoxometalate acid, naphthol.

\section{INTRODUCTION}

Due to the super acidic properties of solid polyoxometalates acids (HPOMs), in the last three decades, polyoxometalates acids have found numerous applications as useful and versatile acid catalyst for some acid-catalyzed reactions [13]. They are usually solids that are insoluble in non-polar solvents but highly soluble in polar ones. They can be used in bulk or supported forms in both homogeneous and heterogeneous systems. Furthermore, polyoxometalates acids have several advantages, including high flexibility in modification of the acid strength, ease of handling, environmental compatibility, and non-toxicity and experimental simplicity [13]. Various polyoxometalates acids in general and Keggin and Well-Dawson acids in particular have attracted considerable amount of interest as acid catalysts for the synthesis of fine chemicals [4]. In spite of vast area of polyoxometalates acids, most of attention has been devoted to the catalytic behavior of Keggin, Well-Dawson and Preyssler type polyoxometalates acids [5-7]. It has been demonstrated recently that the polytungstometalates have high potential as recyclable oxidative catalysts in the synthesis of fine chemicals. However, applications of polytungstometalate acids in acid catalyst reactions are not explored [4-9].

Xanthenes and benzoxanthenes have recently received great attention because of their wide range of therapeutic and biological properties, such as antibacterial [10], antiviral [11], and anti-inflammatory activities [12]. Furthermore, these compounds have emerged as sensitizers in photodynamic therapy, a well known method of controlling the localized tumors [13]. The other useful applications of these heterocycles are as dyes [14] and in laser technologies [15].

Many procedures are disclosed to synthesize xanthenes and benzoxanthenees like cyclodehydrations [16], trapping of benzynes by phenols [17], alkylations $\gamma$ to the heteroatoms

*Address correspondence to these authors at the Department of Chemistry, Shahid Beheshti University, G.C., Tehran 1983963113, Iran; Fax: +98-2122431661; Tel: +98-21-29903104;

E-mails: a_bazgir@sbu.ac.ir,m-pouramini@cc.sbu.ac.ir
[18], and cyclo condensation between 2-hydroxy aromatic aldehydes and 2-tetralone [19]. Furthermore, 14Hdibenzo $[a, j]$ xanthenes and its analogous are prepared by reaction of 2-naphthol with 2-naphthol-1-methanol [20], formamide [21], and carbon monoxide [22].

In spite of potential utility of aforementioned routes for the synthesis of xanthene derivatives, many of these methods involve expensive reagents, strong acidic conditions, long reaction times, low yields, use of excess of reagents/catalysts and use of toxic organic solvents. Therefore, to avoid these limitations, the discovery of a new and efficient catalyst with high catalytic activity, short reaction time, recyclability and simple work-up for the preparation of xanthenes under neutral, mild and practical conditions is of prime interest. The aim of this study is to utilize the polytungstozincate acid as a catalyst for the synthesis of xanthene derivatives.

\section{EXPERIMENTAL}

Melting points were measured on an Elecrtothermal 9100 apparatus and are uncorrected. ${ }^{1} \mathrm{H}$ and ${ }^{13} \mathrm{C}$ NMR spectra were recorded on a BRUKER DRX-300 AVANCE spectrometer at 300.13 and $75.47 \mathrm{MHz}$, respectively. IR spectra were recorded on a Bomem MB-Series FT-IR spectrophotometer. Elemental analyses were performed using a Heracus $\mathrm{CHN}-\mathrm{O}-\mathrm{Rapid}$ analyzer.

\subsection{General Procedure for the Preparation of Catalyst}

Sodium polytungstozincate, $\mathrm{Na}_{12}\left[\mathrm{WZn}_{3}\left(\mathrm{H}_{2} \mathrm{O}\right)_{2}\left(\mathrm{ZnW}_{9}\right.\right.$ $\left.\left.\mathrm{O}_{34}\right)_{2}\right] 46 . \mathrm{H}_{2} \mathrm{O}$, was prepared from $\mathrm{Na}_{2} \mathrm{WO}_{4} \cdot 2 \mathrm{H}_{2} \mathrm{O}$ and $\mathrm{Zn}\left(\mathrm{NO}_{3}\right)_{2} \cdot 6 \mathrm{H}_{2} \mathrm{O}$ in water according to earlier report [23]. For the preparation of parent acid, $\mathrm{Na}_{12}\left[\mathrm{WZn}_{3}\left(\mathrm{H}_{2} \mathrm{O}\right)_{2}\left(\mathrm{ZnW}_{9}\right.\right.$ $\left.\left.\mathrm{O}_{34}\right)_{2}\right] 46 . \mathrm{H}_{2} \mathrm{O}(7.00 \mathrm{~g})$ was dissolved in $\mathrm{H}_{2} \mathrm{O}(100 \mathrm{ml})$ and passed twice through a column $(70 \times 2 \mathrm{~cm})$ of Amberlite IR120 resin (acidic from). Water was removed under reduced pressure at $80^{\circ} \mathrm{C}$ to furnish a light-yellow solid. The polytungstozincate acid was recrystallized from a $\mathrm{H}_{2} \mathrm{O} / \mathrm{DMSO}$ $(2: 5 \mathrm{v} / \mathrm{v})$ solution at room temperature. Formulation of polytungstozincate acid, $\mathrm{H}_{9} \mathrm{Na}_{3}\left[\mathrm{WZn}_{3}\left(\mathrm{H}_{2} \mathrm{O}\right)_{2}\left(\mathrm{ZnW}_{9} \mathrm{O}_{34}\right)_{2}\right] \cdot 24 \mathrm{H}_{2} \mathrm{O}$, was accomplished by thermal analysis (TGA/DTA), titration with base and sodium analysis. 


\subsection{General Procedure for the Preparation of 14-Aryl- 14H-Dibenzo[a,j]Xanthenes}

A mixture of 2-naphthol ( $2 \mathrm{mmol})$, aldehyde (1 mmol) and polytungstozincate acid $(1 \mathrm{~mol} \%, 0.05 \mathrm{~g})$ was heated at $80{ }^{\circ} \mathrm{C}$ for an appropriate time (TLC). After cooling, the reaction mixture was washed with $\mathrm{CHCl}_{3}(10 \mathrm{ml})$. The solvent was evaporated and the crude product recrystallized from EtOH to afford the pure product. The recovered catalysts dried for $1 \mathrm{~h}$ at $100{ }^{\circ} \mathrm{C}$ for investigation of the recyclability of the catalysts.

\subsection{General Procedure for the Preparation of 1,8-Dioxo- Octahydro-Xanthenes}

A mixture of 5,5-dimethyl-1,3-cyclohexanedione (2 mmol), aldehyde (1 mmol) and polytungstozincate acid (1 mol \%, $0.05 \mathrm{~g}$ ) was heated at $80{ }^{\circ} \mathrm{C}$ for an appropriate time (TLC). After cooling, the reaction mixture was washed with $\mathrm{CHCl}_{3}(10 \mathrm{ml})$. The solvent was evaporated and the crude product recrystallized from $\mathrm{EtOH}$ to afford the pure product. The recovered catalysts dried for $1 \mathrm{~h}$ at $100{ }^{\circ} \mathrm{C}$ for investigation of the recyclability of the catalysts.

All the products are known compounds and were characterized by IR and NMR spectroscopic data and their melting points are compared with reported values.

\subsection{General Procedure for the Preparation of 13-Aryl- 13H-6-Oxo-Pentacene-5,7,12,14-Tetraone}

A mixture of 2-hydroxy-1,4-naphthalenedione (2 mmol), aldehyde $(1 \mathrm{mmol})$ and polytungstozincate acid $(1 \mathrm{~mol} \%$, $0.05 \mathrm{~g}$ ) was heated at $80{ }^{\circ} \mathrm{C}$ for an appropriate time (TLC). After cooling, the reaction mixture was washed with hot DMF $(5 \mathrm{ml})$ and DMF filtrated was diluted with water. The separated red solid was filtered under suction and the crude product recrystallized from $\mathrm{EtOH}$ to afford the pure product.

13-Phenyl-13H-6-oxo-pentacene-5,7,12,14-tetraone (8a): m.p. $298-300{ }^{\circ} \mathrm{C}$; IR $(\mathrm{KBr})\left(v_{\max } / \mathrm{cm}^{-1}\right): 3035,1660$, $1569 \mathrm{~cm}^{-1}$; ${ }^{1} \mathrm{H}$ NMR (DMSO- $\left.d_{6}\right): \delta_{\mathrm{H}} 5.09(1 \mathrm{H}, \mathrm{s}, \mathrm{CH}), 7.16-$ 8.08 (13H, m, H-Arom.); MS (m/z, \%): 418 (57), 329 (43), 263 (100). Anal. Calcd (\%) for $\mathrm{C}_{27} \mathrm{H}_{14} \mathrm{O}_{5}$ : C, 77.51; H, 3.37. Found C, 77.64; H, 3.41.

13-(4-Chloro-phenl)-13H-6-oxo-pentacene-5, 7,12,14tetraone $(\boldsymbol{8 b})$ : m.p. 350 dec. ${ }^{\circ} \mathrm{C}$; IR $(\mathrm{KBr})\left(v_{\max } / \mathrm{cm}^{-1}\right): 3028$, $1663,1610 \mathrm{~cm}^{-1} ;{ }^{1} \mathrm{H}$ NMR (DMSO-d $\left.d_{6}\right): \delta_{\mathrm{H}} 5.10(1 \mathrm{H}, \mathrm{s}, \mathrm{CH})$, 7.26-8.07 (12H, m, H-Arom.); MS (m/z, \%): 452 (78), 299 (100). Anal. Calcd (\%) for $\mathrm{C}_{27} \mathrm{H}_{13} \mathrm{ClO}_{5}$ : C, 71.61; H, 2.89. Found C, 71.56; H, 3.93.

13-(4-Methyl-phenyl)-13H-6-oxo-pentacene-5, 7,12,14tetraone $(8 c)$ : m.p. $315-317{ }^{\circ} \mathrm{C}$; IR $(\mathrm{KBr})\left(v_{\max } / \mathrm{cm}^{-1}\right): 3037$, $1662,1608 \mathrm{~cm}^{-1} ;{ }^{1} \mathrm{H}$ NMR (DMSO- $\left.d_{6}\right): \delta_{\mathrm{H}} 2.21\left(3 \mathrm{H}, \mathrm{s}, \mathrm{CH}_{3}\right)$,
5.09 (1H, s, CH), 7.07-8.12 (12H, m, H-Arom.); MS (m/z, \%): 432 (45), 407 (25), 279 (100). Anal. Calcd (\%) for $\mathrm{C}_{28} \mathrm{H}_{16} \mathrm{O}_{5}$ : C, 77.77; H, 3.73. Found C, 77.68; H, 3.66.

13-(2-Chloro-phenyl)-13H-6-oxo-pentacene-5, 7,12,14tetraone $(\boldsymbol{8 d})$ : m.p. $307-310{ }^{\circ} \mathrm{C}$; IR $(\mathrm{KBr})\left(v_{\max } / \mathrm{cm}^{-1}\right): 3037$, $1662,1608 \mathrm{~cm}^{-1} ;{ }^{1} \mathrm{H}$ NMR (DMSO- $\left.d_{6}\right): \delta_{\mathrm{H}} 5.45(1 \mathrm{H}, \mathrm{s}, \mathrm{CH})$, 7.17-8.10 (12H, m, H-Arom.); MS (m/z, \%): 452 (20), 389 (100), 287 (50). Anal. Calcd (\%) for $\mathrm{C}_{28} \mathrm{H}_{16} \mathrm{O}_{5}: \mathrm{C}, 77.77 ; \mathrm{H}$, 3.73. Found C, 77.69; H, 3.78.

\section{RESULTS AND DISCUSSION}

In continuation of our interest on the application of heterogeneous catalysts, especially polyoxometalates acids, for development of useful synthetic methodology [24-26], we wish to report a simple, convenient and efficient method for the synthesis of xanthenes derivatives using polytungstozincate acid as a reusable eco-friendly catalyst under solventfree conditions.

We began to study this condensation reaction by examining the amount of catalysts for the reaction involving 4chloro-benzaldehyde 2c and 2-naphthol 1 to afford the product 3c under solvent-free conditions at $80^{\circ} \mathrm{C}$ (Scheme 1). We found that $0.05 \mathrm{~g}$ of polytungstozincate acid seems to be the optimum amount of catalyst and increasing amount of catalyst did not improve the yields while decreasing the amount of catalyst decreased the yield.

Apparently, reaction of various aromatic aldehydes $\mathbf{2 a - g}$ and 2-naphthol 1 in the presences of the optimized amount of polytungstozincate acid under solvent-free conditions at 80 ${ }^{\circ} \mathrm{C}$ resulted in the formation of 14-aryl-14Hdibenzo $[a, j]$ xanthene 3a-g (Scheme 1). High yields were obtained using aromatic aldehydes carrying electrondonating or electron-withdrawing substituents in 1-2 $\mathrm{h}$ (Table 1), and many problems which many associate with solvent use such as cost, handling, safety and pollution have been avoided.

In aforementioned experiments the catalyst can be isolated by filtration and reloaded with fresh reagents for further runs. No significant leaching of catalyst was observed. Notably recyclization of catalyst is possible for three successive times without significant loss of activity (Table 1, entry 3c). Finally, it should be mentioned when reactions were carried out in the absence of catalyst for long period of time (7-8h) and in solvent-free condition at $80{ }^{\circ} \mathrm{C}$ the yields of products were low $(<30 \%)$.

However, the reaction conducted with 1-naphthol instead of 2-naphthol, could not afford any product. The experimental procedure of the present reaction is simple and the conversion was completed within a short period of time (Table 1).

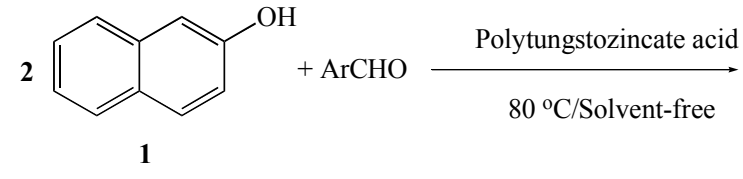

$\mathbf{2 a - h}$<smiles>[Al]C1c2c(ccc3ccccc23)Oc2ccc3ccccc3c21</smiles>

3a-h

Scheme 1. Synthesis of aryl-14H-dibenzo[ $[a, j]$ xanthenes. 
Table 1. Synthesis of Aryl-14H-Dibenzo[a,j]Xanthenes

\begin{tabular}{|c|c|c|c|}
\hline Product 3 & Ar & Time (h) & Yield $(\%)^{a}$ \\
\hline $\mathrm{a}$ & & 1 & 81 \\
\hline $\mathrm{b}$ & & 1.2 & 82 \\
\hline $\mathrm{c}$ & & 1.5 & $88(87,85)^{b}$ \\
\hline $\mathrm{d}$ & & 2 & 91 \\
\hline $\mathrm{e}$ & & 2 & 87 \\
\hline f & & 1 & 89 \\
\hline $\mathrm{g}$ & & 1 & 87 \\
\hline
\end{tabular}

${ }^{\mathrm{a}}$ Isolated yields.

${ }^{\mathrm{b}}$ Isolated yields after recycling of catalyst.

Table 2, compares efficiency of polytungstozincate acid (time, yield, reaction conditions) with efficiency of other catalysts in synthesis of 14-aryl-14H-dibenzo[a,j]xanthene obtained by other groups. It is clear from Table $\mathbf{2}$, our method is simpler, more efficient, and less time consuming for the synthesis of 14-aryl-14H-dibenzo[a,j]xanthene derivatives.

The following mechanism can be proposed and account as a possible pathway for the polytungstozincate acid catalyzed transformation. One molecule of 2-naphthol was firstly condensed with an aromatic aldehyde to afford intermediate 4. The intermediate 4 reacted with another molecule of 2naphthol to afford the corresponding benzoxanthenes (Scheme 2). As shown in Scheme 2, a proton source $\left\{\mathrm{H}_{9} \mathrm{Na}_{3}\left[\mathrm{WZn}_{3}\left(\mathrm{H}_{2} \mathrm{O}\right)_{2}\left(\mathrm{ZnW}_{9} \mathrm{O}_{34}\right)_{2}\right] \cdot 24 \mathrm{H}_{2} \mathrm{O}\right\}$ is necessary for this process.

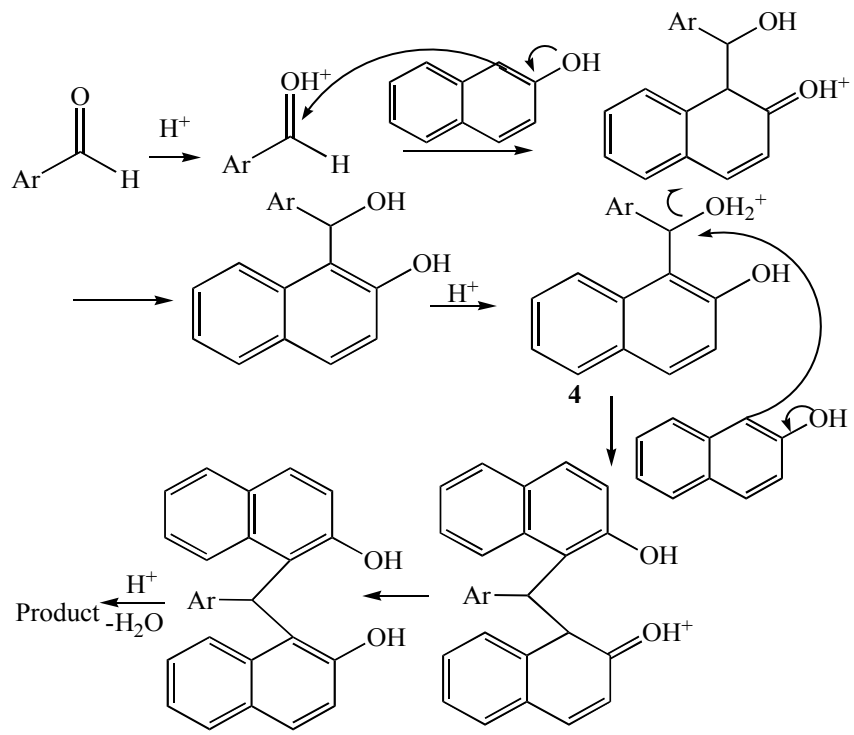

Scheme 2. Proposed mechanism for the synthesis of aryl-14Hdibenzo $[a, j]$ xanthenes.

Encouraged by these results, we replaced the 5,5dimethyl-1,3-cyclohexanedione 5 instead of 2-naphthol $\mathbf{1}$ in the same conditions (Scheme 3). The reaction of 5,5dimethyl-1,3-cyclohexanedione 5 was carried out with various aromatic aldehydes under solvent-free conditions at 80 ${ }^{\circ} \mathrm{C}$, which also afforded 1,8-dioxo-octahydroxanthene derivatives 6a-g in good to high yields within a short period of time (40-80 min, Table 3 ). We have found that the reaction proceeds very efficiently with aromatic aldehydes carrying electron-donating or electron-withdrawing substituents. As can be seen from Table $\mathbf{3}$, in these experiments, recyclization of catalyst is possible for three successive times without significant loss of activity (Table $\mathbf{3}$, entry $\mathbf{6 c}$ ).

The suggested mechanism of the polytungstozincate acid catalyzed transformation is shown in Scheme 4. In this process, polytungstozincate acid is a protonic acid, which catalyzes this reaction.

The efficiency of polytungstozincate acid (time, yield, reaction conditions) are compared with efficiency of other catalysts in synthesis of 1,8-dioxo-octahydroxanthenes and the results are presented in Table 4. It is clear; the present method is simpler, more efficient and less time consuming for the synthesis these compounds.

Similarly, 13-aryl-13H-6-oxo-pentacene-5,7,12,14-tetraone derivatives 8a-d were obtained by the reaction of 2-hydroxy1,4-naphthalenedione 7 and aromatic aldehydes (Scheme 5).

Table 2. Comparison of Efficiency of Various Catalysts in Synthesis of 14-Aryl-14H-Dibenzo[a,j]Xanthene

\begin{tabular}{|c|c|c|c|c|}
\hline Catalyst & Conditions & Yield (\%) & Time (h) & Ref. \\
\hline $\mathrm{H}_{9} \mathrm{Na}_{3}\left[\mathrm{WZn}_{3}\left(\mathrm{H}_{2} \mathrm{O}\right)_{2}\left(\mathrm{ZnW}_{9} \mathrm{O}_{34}\right)_{2}\right] \cdot 24 \mathrm{H}_{2} \mathrm{O}$ & Solvent-free $/ 80^{\circ} \mathrm{C}$ & $81-91$ & $1-2$ & This work \\
\hline Selectfluor $^{\mathrm{Tm}}$ & Solvent-free $/ 125^{\circ} \mathrm{C}$ & $90-95$ & $6-12$ & [27] \\
\hline p-toluene sulfonic acid & Solvent-free $/ 125^{\circ} \mathrm{C}$ & $80-96$ & $2.5-6$ & {$[28]$} \\
\hline p-toluene sulfonic acid & 1,2-dichloroethane(reflux) & $85-95$ & $15-24$ & {$[28]$} \\
\hline $\mathrm{I}_{2}$ & Solvent-free $/ 90^{\circ} \mathrm{C}$ & $85-95$ & $2-5$ & [29] \\
\hline Sulfamic acid & Solvent-free $/ 125^{\circ} \mathrm{C}$ & $90-95$ & $6-12$ & [30] \\
\hline
\end{tabular}


When the reaction was carried out under solvent-free conditions at $80{ }^{\circ} \mathrm{C}$ in the presence of catalyst, the $13 \mathrm{H}$-6-oxopentacene-5,7,12,14-tetraone derivatives 8 were obtained in good yield (Scheme 5), while without catalyst only starting material was recovered. This indicates a catalyst is requiring for this reaction.

Table 3. Synthesis of 1,8-Dioxo-Octahydro-Xanthenes

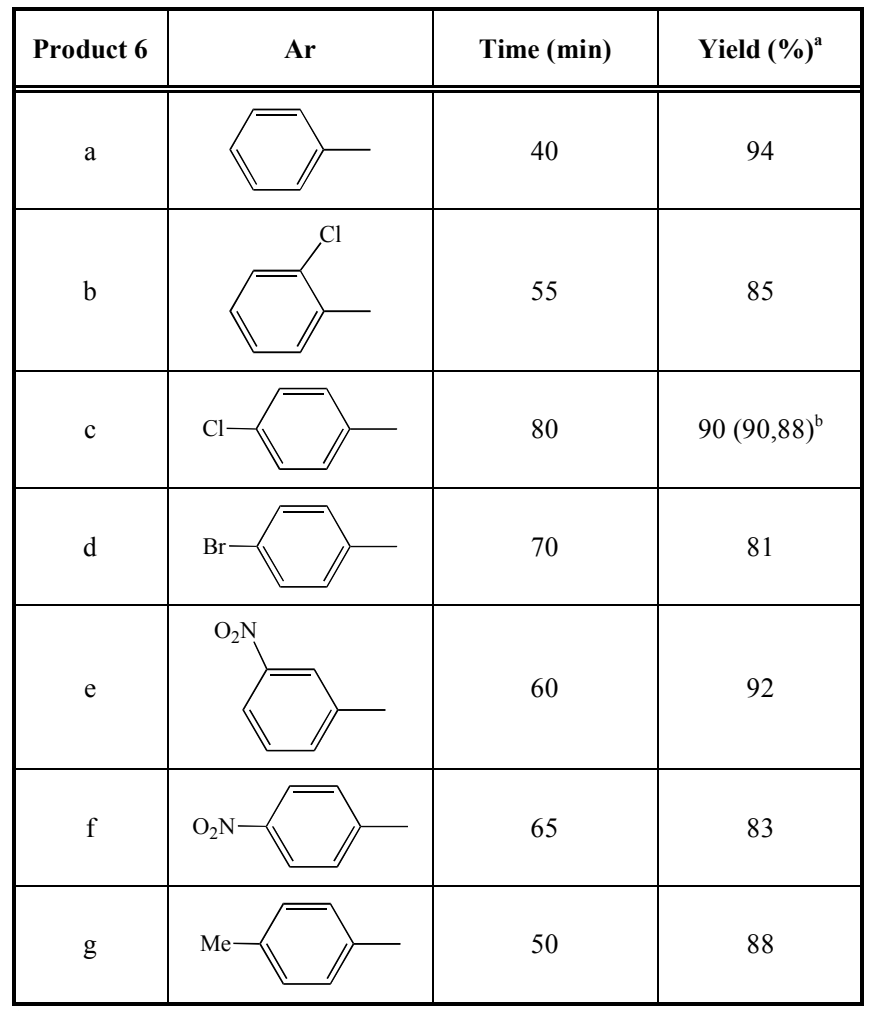

${ }^{a}$ Isolated yields.

${ }^{\mathrm{b}}$ Isolated yields after recycling of catalyst.

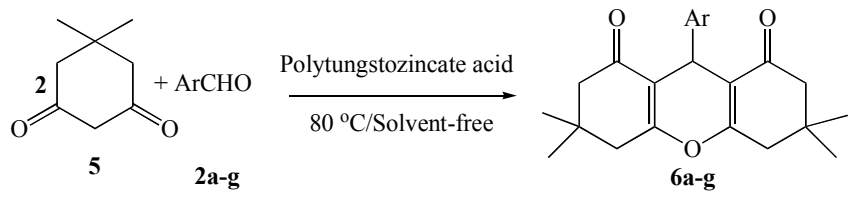

Scheme 3. Synthesis of 1,8-dioxo-octahydro-xanthenes.

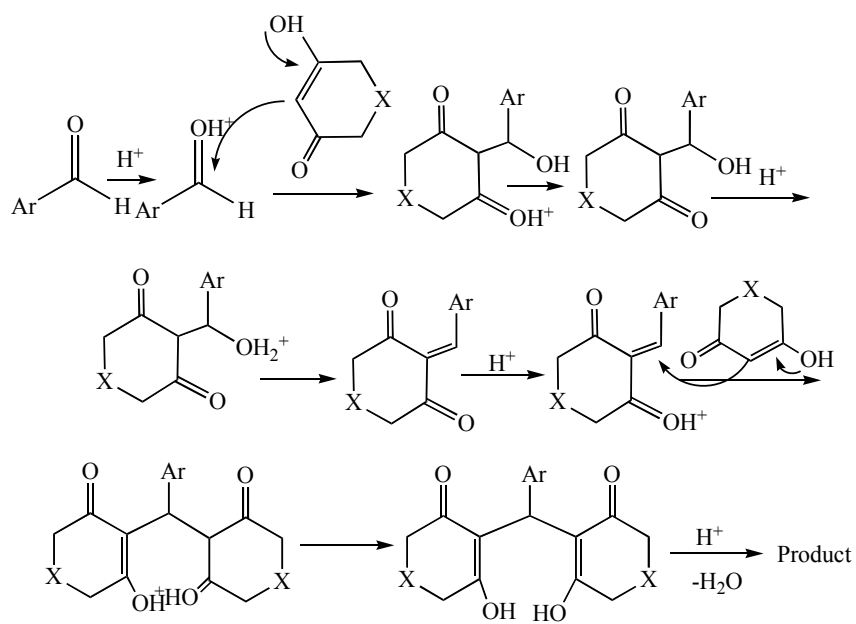

Scheme 4. Proposed mechanism for the synthesis of 1,8-dioxooctahydro-xanthenes.

\section{CONCLUSION}

We have developed a simple, efficient and green methodology for the synthesis of xanthenes using $\mathrm{H}_{9} \mathrm{Na}_{3}\left[\mathrm{WZn}_{3}\left(\mathrm{H}_{2} \mathrm{O}\right)_{2}\left(\mathrm{ZnW}_{9} \mathrm{O}_{34}\right)_{2}\right] \cdot 24 \mathrm{H}_{2} \mathrm{O}$ under solvent-free conditions. The simple experimental procedure, solvent-free reaction conditions, excellent yields and utilization of a reusable catalyst are the advantages of the present method.

Table 4. Comparison of Efficiency of Various Catalysts in Synthesis of 1,8-Dioxo-Octahydro-Xanthenes

\begin{tabular}{|c|c|c|c|c|}
\hline Catalyst & Conditions & Yield (\%) & Time (h) & Ref. \\
\hline $\mathrm{H}_{9} \mathrm{Na}_{3}\left[\mathrm{WZn}_{3}\left(\mathrm{H}_{2} \mathrm{O}\right)_{2}\left(\mathrm{ZnW}_{9} \mathrm{O}_{34}\right)_{2}\right] \cdot 24 \mathrm{H}_{2} \mathrm{O}$ & Solvent-free $/ 80^{\circ} \mathrm{C}$ & $81-93$ & $0.4-1.3$ & This Work \\
\hline $\mathrm{InCl}_{3} \cdot 4 \mathrm{H}_{2} \mathrm{O}$ & Ionic liquide $/ 80^{\circ} \mathrm{C}$ & $76-95$ & $4-10$ & {$[31]$} \\
\hline $\mathrm{Fe}^{3+}$-montmorillonite & EtOH(reflux) & $84-96$ & 6 & {$[32]$} \\
\hline Polyaniline-p-toluenesulfonate & $\mathrm{H}_{2} \mathrm{O}$ (reflux) & $73-84$ & 6 & {$[33]$} \\
\hline $\mathrm{NaHSO}_{4}-\mathrm{SiO}_{2}$ & $\mathrm{CH}_{3} \mathrm{CN}$ (reflux) & $90-98$ & 6 & {$[34]$} \\
\hline Amberlyst- 15 & $\mathrm{CH}_{3} \mathrm{CN}$ (reflux) & $90-96$ & 5 & {$[35]$} \\
\hline
\end{tabular}
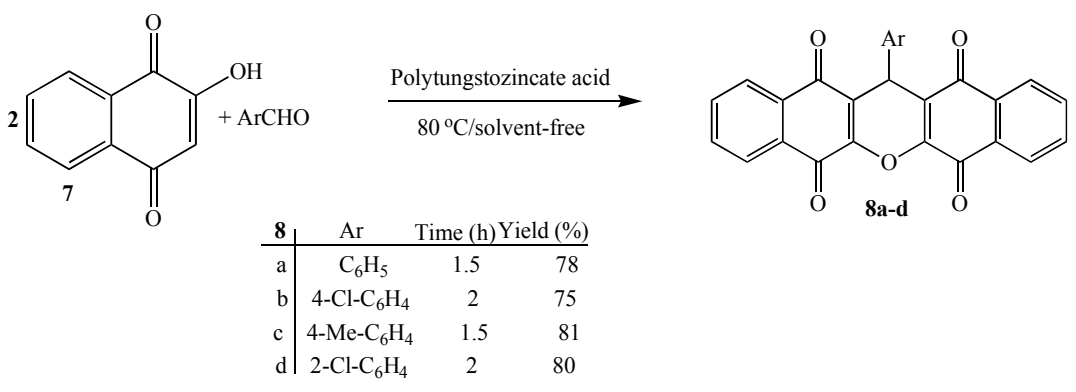

Scheme 5. Synthesis of 13-aryl-13H-6-oxo-pentacene-5,7,12,14-tetraones. 


\section{ACKNOWLEDGEMENTS}

We greatefully acknowledge the financial support from the Research Council of Shahid Beheshti University and CCE.

\section{REFERENCES}

[1] Kozhhevnikov, I.V. Chem. Rev., 1998, 98, 171

[2] Kozhhevnikov, I.V. In Catalysis for Fine Chemical Synthesis, Catalysis by Polyoxometalates 2; Derouane, E., Ed.; Wiley: New York, 2002.

[3] Romanelli, G.P.; Bennardi, D.; Ruiz, D.M.; Baronetti, G.; Thomas, H.J.; Autino, J.C. Tetrahedron Lett., 2004, 45, 8935.

[4] Pope, M.T. Heteropoly and Isopoly Oxometalate; Spring-Verlag: Berlin, 1983.

[5] Morin, P.; Hamad, B.; Sapaly, G.; Carneiro Rocha, M.G.; Pries de Oliveira, P.G.; Gonzalez, W.A.; Andrade Sales, E.; Essayem N. Appl. Catal. A: Gen., 2007, 330, 69.

[6] Cavani, F.; Comuzzi, C.; Dolcetti, G.; Etienne, E.; Finke, R.G.; Selleri, G.; Trifirò, F.; Trovarelli, A. J. Catal., 1996, 160, 317.

[7] Arabi, M.; Amini, M.M.; Abedini, M.; Nemati, A.; Alizadeh, M. $J$. Mol. Catal. A., 2003, 200, 105.

[8] Weinstock, I.A.; Barbuzzi, E.M.G.; Wemple, M.W.; Cowan, J.J.; Reiner, R.S.; Sonnen, D.M.; Heintx, R.A.; Bond, J.S.; Hill, C.L. Nature, 2001, 191

[9] Sioboda-Rozner, D.; Aisters, P.L.; Neumann, R. J. Am. Chem. Soc., 2003, 125,5280

[10] Hideu, T.; Jpn. Tokkyo Koho JP 56005480., 1981 (Chem. Abstr., 1981, 95, 80922b).

[11] Lambert, R.W.; Martin, J.A.; Merrett, J.H.; Parkes, K.E.B.; Thomas, G.J.; PCT Int. Appl. WO 9706178, 1997, (Chem. Abstr., 1997, $126,212377 \mathrm{y})$.

[12] Poupelin, J.P.; Saint-Rut, G.; Fussard-Blanpin, O.; Narcisse, G.; Uchida-Ernouf, G.; Lacroix, R. Eur. J. Med. Chem., 1978, 13, 67.

[13] Ion, R.M.; Frackowiak, D.; Planner, A.; Wiktorowicz, K. Acta Biochim. Pol., 1998, 45, 833.
[14] Banerjee, A.; Mukherjee, A.K. Stain Technol., 1981, 56, 83

[15] Sirkecioglu, O.; Tulinli, N.; Akar, A. J. Chem. Res., 1995, S, 502.

[16] Bekaert, A.; Andrieux, J.; Plat, M. Tetrahedron Lett., 1992, 33 , 2805.

[17] Knight, D.W.; Little, P.B. J. Chem. Soc. Perkin Trans., 2001, I14, 1771 .

[18] Ishibashi, H.; Takagaki, K.; Imada, N.; Ikeda, M. Synlett., 1994, 49.

[19] Jha, A.; Beal, J. Tetrahedron Lett., 2004, 45, 8999.

[20] Sen, R.N.; Surkar, N.N. J. Am. Chem. Soc., 1925, 47, 1079.

[21] Papini, P.; Cimmarusti, R. Gazz. Chim. Ital., 1947, 77, 142.

[22] Ota, K.; Kito, T. Bull. Chem. Soc. Jpn., 1978, 49, 1167.

[23] Tourne, C.M.; Tourne, G.F.; Zonnevijlle, F. J. Chem. Soc. Dalton Trans., 1991, 143.

[24] Amini, M.M.; Seyyedhamzeh, M.; Bazgir, A. Appl. Catal. A: Gen., 2007, 323, 242.

[25] Amini, M.M.; Shaabani, A.; Bazgir, A. Catal. Commun., 2006, 7 , 843.

[26] Imani-Shakibaei, G.; Mirzaei, M.P.; Bazgir, A. Appl. Catal. A: Gen., 2007, 325, 188.

[27] Kumar, P.S.; Kumar, B.S.; Rajitha, B.; Reddy, P.N.; Sreenivasulu, N.; Reddy, Y.T. Arkivoc xii., 2006, 46.

[28] Khosropour, A.R.; Khodaei, M.M.; Moghannian, H. Synlett., 2005, 955.

[29] Das, B.; Ravikanth, B.; Ramu, R.; Laxminarayana, K.; Vittal Rao, B. J. Mol. Catal. A: Chem. 2006, 255, 74 .

[30] Rajitha, B.; Kumar, B.S.; Reddy, Y.T.; Reddy, P.N.; Sreenivasulu, N. Tetrahedron Lett., 2005, 46, 8691.

[31] Fan, X.; Hu, X.; Zhang, X.; Wang, J. Can. J. Chem., 2005, 83, 16.

[32] Song, G.; Wang, B.; Luo, H.; Yang, L. Catal. Commun., 2007, 8, 673.

[33] John, A.; Yadav, P.J.P.; Palaniappan, S. J. Mol. Catal. A: Chem., 2006, $248,121$.

[34] Das, B.; Thirupathi, P.; Reddy, K.R.; Ravikanth, B.; Nagarapu, L. Catal. Commun., 2007, 8, 535 .

[35] Das, B.; Thirupathi, P.; Mahender, I.; Reddy, V.S.; Rao, Y.K. Mol. Catal. A: Chem., 2006, 247, 233.

This is an open access article licensed under the terms of the Creative Commons Attribution Non-Commercial License (http://creativecommons.org/licenses/by$\mathrm{nc} / 3.0 /$ ) which permits unrestricted, non-commercial use, distribution and reproduction in any medium, provided the work is properly cited. 